undeformed cars. Again no occupant was wearing a seat belt. Good protection would have been given to five.

\section{Discussion}

National figures are not available for the numbers of deaths due to collisions of cars and lorries. Among 296 deaths of car occupants within 12 hours of injury, Ruffel Smith (1970) found that more than half were due to collisions with lorries. In our present series of 564 car occupant deaths $40 \%$ were from such collisions. It is difficult to apply appropriate weightings for different traffic conditions, but if $40 \%$ is a fair estimate it implies that in Great Britain car/lorry collisions cause about 1,000 deaths annually. This is as many as all the deaths due to accidents at work as studied by the recent Robens inquiry (Secretary of State for Employment, 1972).

At first sight it is surprising that these collisions should be so common since lorries are outnumbered by cars by $7-1$. The explanation seems to be an incompatability between the two types of vehicle. The lorry is heavy and strongly built to carry heavy loads. Rising gradients slow it down, falling gradients may cause it to go out of control. The car by contrast is light and built to maintain high speeds with light loads. Grime (1971) studied the theoretical mechanics of impacts between vehicles of different sizes. Of the lorries in our survey of which we know the weights, more than half were over 5 tons unladen. Most of the collisions, therefore, had a "mass-ratio" of at least 5 . In Grime's analysis this implies a $95 \%$ or more risk of serious injury to car occupants with virtually no risk to the lorry occupants. This is consistent with our finding of 224 deaths of car occupants with five deaths of those in lorries.

The unfavourable terms of this conflict has important implications for methods of protection. Whereas several studies show that seat belts will prevent $50 \%$ of injuries to car occupants, in our car/lorry collisions we estimate this could be only about $20 \%$. The figure falls to about $10 \%$ for collisions of cars into the rear of lorries where so often the rear overhang or protruding load penetrates the windscreen area and so eliminates the protection normally afforded by the front of the car.

Collisions into the rear of lorries are several times more frequent in dark than in light conditions in spite of there being less traffic of all kinds at night. This suggests there is room for improvement in making lorries more conspicuous. The current experiment with extra coloured markings may yield some benefit and there could well be other ways to warn motorists of impending danger. Elimination of the rear overhang of lorries and improved lighting might prevent some of the worst collisions but the underlying incompatibility of light and heavy vehicles remains. A more fundamental solution is the segregation of the two types of traffic on separate roads as on some highways in the United States. Another solution, perhaps more appropriate to this country, is to take account of the impending world shortage of oil supplies and save both fuel and human lives by using rail rather than road transport.

We wish to thank Miss B. Roberts, for her help in this analysis, and the coroners and police of the areas studied, for their kind co-operation.

The earlier part of this study was supported by a grant from the Automobile Association, but the recommendations are the sole responsibility of the authors.

\section{References}

Grime, G. (1971). Effect of Vehicle Mass on Risk of Injury in a Collision. London, University College.

Ruffell Smith, H.P. (1970). A Study of Fatal Injuries in Vehicle Collisions Based on Coroners' Reports. LR 316 . Crowthorne, Road Research Laboratory. p. 161 . London, H.M.S.O.
.

\title{
Immunological Abnormalities in Juvenile Myelomonocytic Leukaemia
}

\section{ARLETTE CANNAT, MAXIME SELIGMANN}

British Medical fournal, 1973, 1, 71-74

\section{Summary}

Immunological studies were performed on 24 children suffering from juvenile myelomonocytic leukaemia. Strikingly high serum immunoglobulin levels with a frequent tendency towards homogeneity and light-chain imbalance were present, together with a high incidence of antinuclear antibodies (52\%) and antihuman IgG antibodies $(43 \%)$. Members of the families of 19 of the children were also studied. A few similar abnormalities were found in eight families, mostly clustered in four of them. The significance of the association of these immunological aberrations with juvenile myelomonocytic leukaemia is at present unknown. In view of the interrelation observed in experimental models between immunological abnormalities and oncogenic viruses the possibility of a common aetiological factor such as a viral infection during fetal life is suggested.

\footnotetext{
Department of Immunochemistry, Research Institute on Blood Diseases, Hôpital Saint-Louis, Paris 10e, France ARLETTE CANNAT, M.D., Maître de Recherches à I'I.N.S.E.R.M. MAXIME SELIGMANN, M.D., Professor
}

\section{Introduction}

Juvenile myelomonocytic leukaemia is an uncommon condition, and should be regarded as a separate entity from the chronic granulocytic leukaemia of adult type which may occur in childhood (Bernard et al., 1962). The two diseases differ in many clinical and haematological features. The myelomonocytic type occurs in infants and very young children, and is usually characterized by greater lymph node enlargement, frequent cutaneous manifestations which may be of xanthomatous type, early onset of thrombocytopenia, lower total leucocyte count with fewer myelocytes but a higher proportion of monocytes, hypochromic anaemia, and presence of normoblasts in the peripheral blood. The absence of the Philadelphia chromosome in the bone marrow cells of these children (Reisman and Trujillo, 1963; Hardisty et al., 1964) provides strong support for regarding juvenile myelomonocytic leukaemia as different from chronic myeloid leukaemia. The extreme variability of the course, together with the unpredictable prognosis in children affected with this condition, raise the possibility that it is not a single disease entity (Bernard and Seligmann, 1968).

A number of peculiar biological features such as very high blood levels of fetal haemoglobin (Hardisty et al., 1964; Miller, 1969), modifications of blood group antigens, and hypergammaglobulinaemia (Bernard and Seligmann, 1968) are frequently found in these children. Whereas high levels of $\mathrm{Hb} \mathrm{F}$ are found mainly in cases with poor prognosis, hypergammaglobulinaemia is an almost constant feature of this condition whatever its 
ultimate evolution. This finding led us to a systematic study of the immunoglobulins and a search for different kinds of autoantibodies in 24 children with juvenile myelomonocytic leukaemia whose clinical and haematological data have been reported in another paper (Weisgerber et al., 1972).

\section{Patients and Methods}

We have studied 185 serum samples. They included 90 samples from 24 consecutive unselected patients with juvenile myelomonocytic leukaemia, 69 samples from members of the families of 19 of these children, and 26 pretreatment samples from children matched for age and suffering from acute lymphoblastic (19) or acute myeloblastic (7) leukaemia. No normal matched controls were included in this study since normal values for children have previously been defined in this and other laboratories for the different measurements involved.

Of the 24 children with juvenile myelomonocytic leukaemia, 20 were boys. The age of onset varied from 4 months to 5 years, with 11 patients under 12 months and only one above 3 years old. From most patients, samples were collected at different stages of their illness: in periods of active disease before and during treatment, in quiescent periods, and during clinical and haematological remission when such an event occurred. For seven children, however, no sample was available before treatment, and two other children were studied only when in remission for several years.

Immunoglobulin Measurements.-Immunoglobulin concentrations were determined by the quantitative single radial immunodiffusion method (Mancini et al., 1965) using monospecific rabbit antisera prepared in our laboratory. Our normal mean values for adults are: $11.7 \pm 2.7$ ( 1 S.D.) $\mathrm{mg} / \mathrm{ml}$ for IgG; $2.2 \pm 0.8 \mathrm{mg} / \mathrm{ml}$ for IgA; and $1.2 \pm 0.5 \mathrm{mg} / \mathrm{ml}$ for IgM. Our values for children are in good agreement with those established in other laboratories by studying a greater number of sera (Stiehm and Fudenberg, 1966; Buckley et al., 1968; Hobbs, 1970).

Electrophoretic and Immunoelectrophoretic Studies.-Paper and agar-gel electrophoresis was performed on every sample as well as immunoelectrophoresis with polyvalent antisera and with an antiserum to normal human IgG. Monospecific antisera to $\gamma, \mu, \alpha, x$, and $\lambda$ chains were prepared by suitable absorption and were used in most cases. The antisera to light chains were selected for their ability to precipitate strongly with $\operatorname{IgG}, \operatorname{IgA}$, and IgM molecules of the corresponding light-chain type. A tendency towards electrophoretic homogeneity was assumed in the presence of an electrophoretic pattern showing a discrete band in the $\beta 2$ - or $\gamma$-globulin region and of a deflexion of the immunoelectrophoretic precipitin line corresponding to one heavy-chain class and a single light-chain type. Imbalance of light-chain types of IgG molecules was detected by immunoelectrophoresis and double diffusion techniques using simultaneously anti- $x$ and anti- $\lambda$ antisera which had been absorbed so as not to react with one another by antigen excess, and evaluating the position and intensity of the IgG precipitin lines in comparison with normal control sera (Seligmann et al., 1967). Disproportionate ratios of light-chain types in IgM molecules were appreciated by the same technique using fractions obtained by ultracentrifugation on a sucrose density gradient (Hurez, 1967). Only gross changes in the ratio of $x$ to $\lambda$ light chains were regarded as significant - that is, near absence of $\lambda$-chain molecules or preponderance of $\lambda$ over $x$ molecules. The imbalance as regards the $\gamma$-chain subclasses was investigated by Dr. W. Yount using quantitative methods (Yount et al., 1970). The monomeric $7 \mathrm{~S}$ IgM was sought by double diffusion in polyacrylamide agarose gel (Brouet, 1972), and by double diffusion in agar using sucrose density gradient $7 \mathrm{~S}$ fractions.

Autoantibodies.-Antinuclear antibodies, antigastric parietal cell antibodies, and antimitochondrial antibodies were sought by indirect immunofluorescence using rat liver, rat stomach, and rat kidney as substrates and an antihuman immunoglobulin antiserum conjugated with fluorescein isothiocyanate.

Antithyroglobulin antibodies were sought by passive haemagglutination using a commercial preparation (Wellcome Reagents).

Antibodies to $\gamma$-globulin were sought in samples collected before any blood transfusion by the Singer-Plotz antihuman $\gamma$-globulin technique on slides and in tubes and by the WaalerRose technique with rabbit $\gamma$-globulins.

Examination of the Immune Response.-Levels of isohaemagglutinins and of antistreptolysin $\mathrm{O}$ were titrated as well as levels of diphtheria and tetanus antitoxins and of poliovirus antibodies (sero-neutralization), after vaccination and correct challenge. Evaluation of delayed hypersensitivity was performed by studying intradermal reactions to candidin, tuberculin, and streptokinase-streptodornase and sensitization to dinitrochlorobenzene. Phytohaemagglutinin-induced transformation of lymphocytes was assessed in a limited number of patients.

\section{Results}

\section{IMMUNOGLOBULINS}

\section{Quantitative Aspects}

Nineteen of the 24 patients had $\gamma$-globulin concentrations of more than $20 \mathrm{~g} / 1$. On paper electrophoresis at one time or another, the maximum levels being 41 and $42 \mathrm{~g} / \mathrm{l}$. for children of 10 months and 5 years of age respectively. Of 24 patients only three had $\gamma$-globulin levels of less than $15 \mathrm{~g} / \mathrm{l}$., and they were 5 months, 1 year, and $3 \frac{1}{2}$ years old. IgG, IgM, and IgA concentrations are shown in figs. 1, 2, and 3. The figures for IgG and IgM were strikingly high for most patients. Indeed IgG

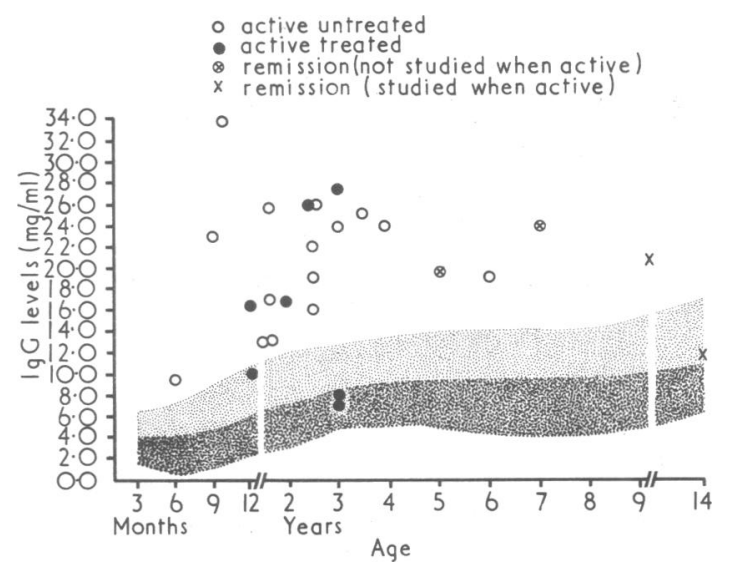

FIG. 1.-Levels of IgG in the 24 patients. Shaded areas = normal (mean \pm 2 S.D.).

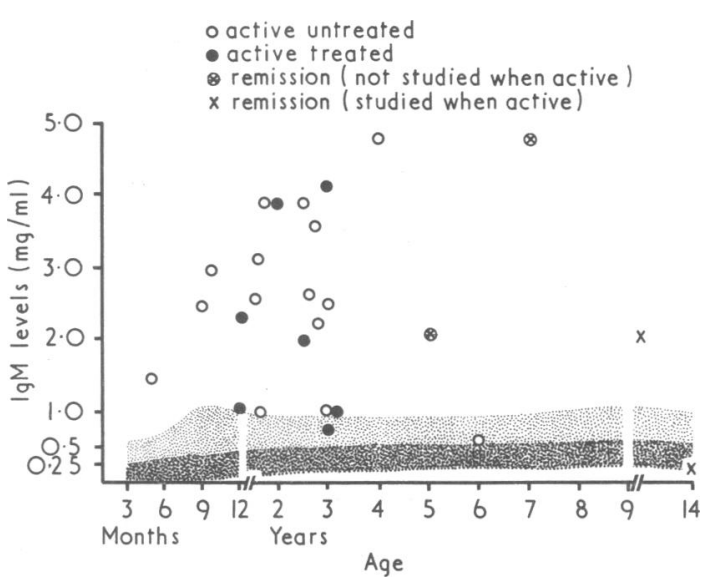

FIG. 2-Levels of IgM in the 24 patients. Shaded areas = normal (mean \pm 2 S.D.) 


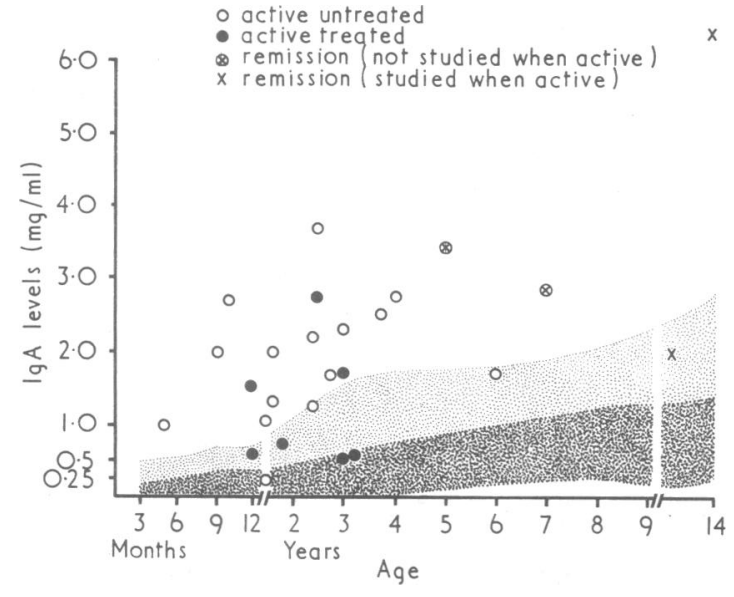

FIG. 3-Levels of IgA in the 24 patients. Shaded areas $=$ normal (mean \pm 2 S.D.).

concentrations for all but two patients with active disease were well above the mean normal value plus 2 S.D. and the IgG level was above $20 \mathrm{mg} / \mathrm{ml}$ in as many as 10 children under 5 years old. The IgM concentration was above the mean normal value plus 2 S.D. for 17 of 22 patients with active disease and these figures were not affected by 7S IgM, the absence of which from the sera was ascertained. IgA levels were above the normal range in half of the active patients (fig. 3).

These high values were always confirmed on several successive samples and as a rule they remained high under treatment with corticoids or chemotherapy or both. In only one case the values were significantly lower under treatment and became practically normal when the patient was greatly improved after several years. A striking fact, however, is that the four patients who were in complete remission for several years and usually treated with mercaptopurine remained hypergammaglobulinaemic (between 18 and $30 \mathrm{~g} / 1$.) and had significantly high values for all or some Ig classes.

\section{Restricted Heterogeneity and Light-chain Imbalance}

IgG molecules with slow electrophoretic mobility were predominantly increased in practically all patients. A tendency towards electrophoretic homogeneity of IgG or IgM or both was observed in six patients, one of whom also excreted a small amount of urinary Bence Jones kappa protein.

Disproportionate ratios of $x$ to $\lambda$ light-chain types of IgG molecule were observed in three out of 17 patients studied. Moreover, a gross predominance of $\operatorname{IgM} \lambda$ over $\operatorname{IgM} \times$ molecules was observed in six out of 12 patients studied. No imbalance as regards IgG subclasses distribution was seen.

\section{AUTOANTIBODIES}

As shown in the table, 11 of 21 patients with active disease had antinuclear factors in their sera and nine had antibodies to human $\gamma$-globulin. For three patients autoantibody studies were not performed on active-stage samples, and only one of these was positive for both antinuclear factor and rheumatoid factor while in haematological remission. In this boy, aged 14, Schönlein-Henoch purpura and a nephrotic syndrome appeared several years after remission of the juvenile myelomonocytic leukaemia.

Most sera positive for antinuclear factor showed a low or moderate titre and all gave a speckled pattern of fluorescence. Rheumatoid factors in all positive cases were directed against human IgG. The Waaler-Rose test against rabbit $\gamma$-globulin was positive in only two of these patients and with a very low titre. There was a certain amount of correlation between positive antinuclear factor and positive rheumatoid factor tests since
Autoantibodies in 21 Patients Studied in an Acute Phase

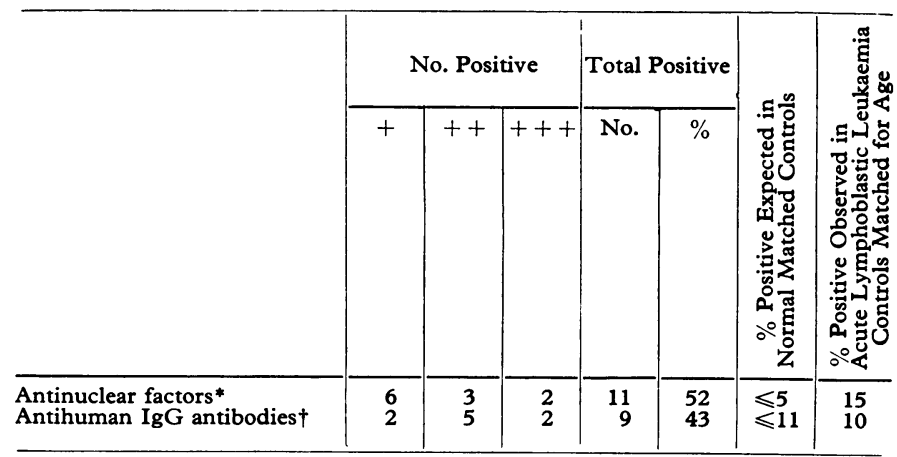
* Antinuclear factor titres: $+\leqslant 1 / 10,++>1 / 10<1 / 100,+++\geqslant 1 / 100$
+ F II latex titres: $+1 / 80$ to $1 / 200,++1 / 200$ to $1 / 2,000+++>1 / 2,000$.

these two tests were both positive in as many as eight patients. On the other hand, there was no correlation between the results of either antinuclear factor or rheumatoid factor tests and such features as degree of increase in Ig levels, light-chain imbalance, repeated infections, or further clinical evolution.

Tests for gastric and mitochondrial autoantibodies were negative in all 24 patients whether the disease was active or quiescent. One child aged 3 years had thyroglobulin antibodies at a moderate titre.

\section{IMMUNE RESPONSES}

The occurrence of repeated infections before the onset of juvenile myelomonocytic leukaemia in 12 of 24 patients, together with the Ig abnormalities observed, suggested some impairment of immune responses. However, no significant abnormalities were found in the 10 children whom it was possible to investigate.

\section{FAMILY STUDIES}

The 69 serum samples studied were from 31 fathers and mothers under 40 years old, four grandfathers or grandmothers, and 34 siblings aged 2-12 years.

The incidence of abnormalities was not high enough to be statistically significant (antibodies to human $\gamma$-globulin in 5\%, abnormally high Ig levels in 7\%) except perhaps in the case of antinuclear antibodies $(20 \%$ positive sera). These few abnormalities, however, were not scattered among the 19 families studied. They were detected in only eight families, and indeed seemed to be mostly clustered in four of them. For instance, in one family antinuclear factor was detected in the mother and five of seven siblings aged 3 to 10 years, two of whom had $\gamma$-globulin levels of 20 and $21 \mathrm{~g} / 1$; in another family both young and healthy parents showed antibodies to human $\gamma$-globulin.

\section{Discussion}

The immunological abnormalities thus observed in juvenile myelomonocytic leukaemia include strikingly high serum immunoglobulin levels with a frequent tendency towards homogeneity and light-chain imbalance, a high incidence of antinuclear and antihuman IgG antibodies, and a moderate number of familial abnormalities.

These findings are striking both per se and when compared with those in other varieties of leukaemia in children (Seligmann et al., 1959; Kiran and Gross, 1969; Cannat et al., 1969). It should be noted in this connexion that the high proportion of boys and the early age of onset in juvenile myelomonocytic leukaemia made it difficult to obtain correctly matched controls. 
Sera from only 19 patients with acute lymphoblastic and seven with acute myeloblastic leukaemia, untreated and matched for age but not always for sex, were available.

No significant immunoglobulin abnormality was detected in these leukaemic controls, whose immunoglobulin concentrations were always within the normal range. Antibodies to $\gamma$-globulin have been observed in $6-11 \%$ of very young normal untransfused children (Stiehm and Fudenberg, 1965; Wilson and Steinberg, 1965) and were also found in $10 \%$ of our leukaemic controls. On the other hand, antinuclear antibodies, present in our experience in less than $5 \%$ of normal children, were found in $15 \%$ of the controls with lymphoblastic leukaemia and in three of the seven very young children with myeloblastic leukaemia. We know nothing of the significance of these antinuclear antibodies in juvenile or adult leukaemia (Cannat et al., 1969).

High immunoglobulin levels (Seligmann et al., 1959) and the presence of antileucocyte autoantibodies (Seligmann et al., 1954; Killmann, 9157) were described many years ago in adult monocytic or myelomonocytic leukaemia. We have more recently encountered many immunological abnormalities in several such adult patients. Osserman (1967) found significant quantitative abnormalities in the serum immunoglobulin concentrations in nine of 12 adult patients affected with monocytic or myelomonocytic leukaemia, three of whom showed a monoclonal type of immunoglobulin. He also found a pronounced increase in the level of serum and urinary lysozyme in all these patients. This increase in lysozyme level was present in all of 12 patients with juvenile myelomonocytic leukaemia in the present series who were studied by Osserman. It has also been observed in an experimental model of myelomonocytic leukaemia (Warner et al., 1969), and it is noteworthy that this model was obtained in BALB/c mice with the procedure currently used for producing plasma cell tumours.

Immunological abnormalities similar to those reported in the present study have been observed in patients affected with other atypical myeloproliferative disorders-namely, in those conditions grouped by Dameshek under the heading of Di Guglielmo syndrome (Finkel et al., 1966) and in patients with a longstanding and moderate marrow infiltration with myeloblasts (Cannat et al., 1969). It is of interest to note that modifications of blood group antigens and red cell enzyme changes have been observed in refractory anaemia with excess of myeloblasts in the bone marrow (Dreyfus et al., 1969) as well as in children with juvenile myelomonocytic leukaemia (Weatherall et al., 1968; Weisgerber et al., 1972) together with a high level of $\mathrm{Hb} \mathrm{F}$ and increased autohaemolysis.

We found no correlation between the erythrocytic abnormalities, which were present in only some cases of juvenile myelomonocytic leukaemia, and the severity of the immunological abnormalities, which were present in all patients whatever their ultimate prognosis and which persisted during complete remission.

The significance of the immunological aberrations found in this disease is at present unknown. Rather than looking at them as the expression of a predisposition to leukaemia or as the consequence of a struggle against the leukaemic process, we should like to suggest, in view of their association with so many different haematological abnormalities, the possibility of a common aetiological factor such as a viral infection during fetal life. This hypothesis is consistent with the findings in various experimental models - that is, the correlations between viral infection, autoimmunity, and malignancy in NZ mice (Mellors et al., 1969; East, 1970), the occurrence of immunoglobulin abnormalities in Aleutian mink disease (Porter et al., 1965), and the autoimmune phenomena occurring in graft-versus-host disease (Schwartz and André-Schwartz, 1968). In all these models the genetic background is of some importance. The present results and the familial occurrence of myeloproliferative diseases resembling juvenile myelomonocytic leukaemia (Randall et al., 1965; Holton and Johnson 1968) suggest that it may also play a part in these conditions.

On the whole, we believe that the immunological abnormalities in juvenile myelomonocytic leukaemia, although they remain as yet unexplained, could well provide a clue to a better understanding of this disease and perhaps of other leukaemias.

We thank Dr. Françoise Danon and Chantal Weisgerber for their help in this work.

This study was supported in part by the French National Institute for Health and Medical Research (I.N.S.E.R.M.).

\section{References}

Bernard, T., Seligmann, M., and Acar, J. (1962). Archives Françaises de Pédiatrie, 19,881.

Bernard, J., and Seligmann, M. (1968). Nouvelle Revue Française d'Hématologie, 8,759 .

Brouet, J. C. (1972). Revue Européenne d'Etudes Cliniques et Biologiques. 17,801

Buckley, R. H., Dees, S. C., and O'Fallon, M. (1968). Pediatrics, 41, 600. Cannat, A., and Rain, J. D., and Seligmann, M. (1969). Nouvelle Revue Fran caise d'Hématologie, $9,290$.

Dreyfus, B., et al. (1969). British fournal of Haematology, 16, 303

East, J. (1970). Progress in Experimental Tumor Research, 13, 84.

Finkel, H. E., Brauer, M. J., Taub, R. N., and Dameshek, W. (1966). Blood, 28,634 .

Hardisty, R. M., Speed, D. E., and Till, M. (1964). British fournal of Haematology, 10, 551 .

Hobbs, J. R. (1970). Association for Clinical Pathologists, Broadsheet No. 68, p. 1 .

Holton, C. P., and Johnson, W. W. (1968). Fournal of Pediatrics, 72, 377.

Hurez, D. (1967). Revue Fran caise d'Etudes Cliniques et Biologiques, 12, 915. Killmann, S. A. (1957). Acta Haematologica, 17, 360.

Kiran, O., and Gross, S. (1969). Blood, 33, 198.

Mancini, G., Carbonara, A. O., and Heremans, J. F. (1965). Immunochemistry, 2, 235.

Mellors, R. C., Aoki, T., and Huebner, R. J. (1969). Fournal of Experimental Medicine, 129,1045 .

Miller, D. R. (1969). British fournal of Haematology, 17, 103.

Osserman, E. F. (1967). In Nobel Symposium 3. Gamma globulins. Structure and Control of Biosynthesis, ed. J. Killander, p. 574. Stockholm, Almqvist and Wiksell.

Porter, D. D., Dixon, F. J., and Larsen, A. E. (1965). Blood, 25, 736

Randall, D. L., Reiquam, C. W., Githens, J. H., and Robinson, A. (1965). American fournal of Diseases of Children, 110, 479 .

Reisman, L. E., and Trujillo, J. M. (1963). Fournal of Pediatrics, 62, 710.

Schwart, R. S., and André-Schwartz, J. (1968). Annual Review of Medicine, 19,274 .

Seligmann, M., Alais, L., and Bernard, J. (1959). Revue Française d'Etudes Cliniques et Biologiques, 4, 901.

Seligmann, M., Grabar, P., and Bernard, J. (1954). Vox Sanguinis, 4, 181.

Seligmann, M., Meshaka, G., and Danon, F. (1967). Revue Française d'Etudes Cliniques et Biologiques, 12, 604 .

Stiehm, E. R., and Fudenberg, H. H. (1965). Pediatrics, 35, 229.

Stiehm, E. R., and Fudenberg, H. H. (1966). Pediatrics, 37, 715.

Warner, N. L., Moore, M. A. S., and Metcalf, D. (1969). Fournal of National Cancer Institute, 43, 963.

Weatherall, D. J., Edwards, J. A., and Donohoe, W. T. A. (1968). British Medical fournal, 1, 679.

Weisgerber, C., Schaison, G., Chavelet, F., Seligmann, M., and Bernard, J. (1972). Archives Françaises de Pédiatrie, 29, 11 .

Wilson, J. A., and Steinberg, A. G. (1965). Transfusion, 5, 516.

Yount, W. J., Hong, R., Seligmann, M., Good, R. A., and Kunkel, H. G. (1970). Fournal of Clinical Investigation, 49, 1957. 